Check for updates

Cite this: RSC Adv., 2022, 12, 7313

Received 17th February 2022

Accepted 24th February 2022

DOI: $10.1039 / \mathrm{d} 2 \mathrm{ra01062c}$

rsc.li/rsc-advances

\section{Study of the Pauson-Khand reaction in flow over alkynylphenyl vinyl ethers: towards the synthesis of tricyclic multisubstituted benzofurans $\dagger$}

\author{
Jorge García-Lacuna, (D) Maialen Alonso, Gema Domínguez and Javier Pérez \\ Castells (iD *
}

\begin{abstract}
The use of flow methodology allows the use of alkynylphenyl vinyl ethers (benzo-fused 1,7 enynes) as substrates for the intramolecular Pauson-Khand reaction ( $\mathrm{PKr}$ ). Forced temperature and pressure conditions during a short reaction time minimize the substrate decomposition allowing the formation of the PK adduct. Substrates substituted at the internal position of the double bond and with internal triple bonds give better yields. The resulting products are cyclopentabenzofuranones present in diverse natural products and drugs that can be further functionalised.
\end{abstract}

\section{Introduction}

The Pauson-Khand reaction (PKr) is a formal $[2+2+1]$ cycloaddition of an alkyne, an alkene and a carbonyl unit to give a cyclopentenone. Until the late 1990 s it was mediated by a stoichiometric amount of metal, generally a cobalt carbonyl complex. The industrial applicability of this reaction was limited due to the use of either stoichiometric or harsh catalytic conditions (high carbon monoxide pressures and elevated temperatures). ${ }^{1}$ In 2017, our group developed a flow protocol for both intra- and intermolecular Pauson-Khand reactions, using catalytic amounts of $\mathrm{Co}_{2}(\mathrm{CO})_{8}$ in a plug flow reactor. ${ }^{2}$ The applicability, robustness and safety of the process were proved in several gram scale syntheses and it was also applied in the key step of the synthesis of the commercial drug treprostinil. ${ }^{3} \mathrm{~A}$ photochemically triggered stoichiometric $\mathrm{PKr}$ in flow was described using preformed alkyne-cobalt complexes. ${ }^{4}$

The field of flow chemistry has gained considerable attention along the last decade. Flow methods are generally faster, safer and greener. They enable safer handling of hazardous reagents and better mixing of biphasic regimes, in some cases reactions that are difficult or impossible to do in the batch mode are made possible. ${ }^{5}$ In particular, flow technologies are highly advantageous when using toxic gases like CO, particularly if harsh conditions are needed. ${ }^{6}$ All these advantages explain the high number of continuous flow protocols being used for the

Department of Chemistry and Biochemistry, Facultad de Farmacia, Universidad San Pablo-CEU, CEU Universities, Urbanización Monteprincipe, 28660 Boadilla del Monte, Madrid, Spain. E-mail: jpercas@ceu.es

$\dagger$ Electronic supplementary information (ESI) available: Detailed experimental procedures, spectroscopical data and copies of NMR spectra of all new compounds. See DOI: 10.1039/d2ra01062c synthesis of pharmaceuticals or important building blocks, with special attention to industrial applicability. ${ }^{7}$

Despite the great number of substrates used to date, vinyl ethers continue to be challenging substrates for the $\mathrm{PKr}^{8}{ }^{8}$ Only three reports, where these motifs were used as PK substrates have been reported. In 1981, Croudace and Schore attempted to use several vinyl ethers in an intramolecular PKr. They observed the expected reaction with cobalt complexes, but the subsequent isolation of the cyclopentenone was unsuccessful. ${ }^{9}$ Later, examples of the intramolecular version provided only moderate yields and the cleavage of the vinyl ether structure in the final product. The vinyl ether acted, thus, as ethylene surrogate (Scheme 1). ${ }^{10}$

a) Schore

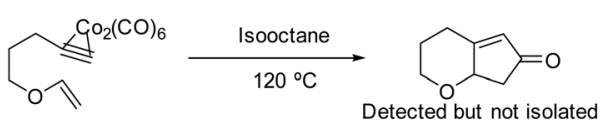

b)

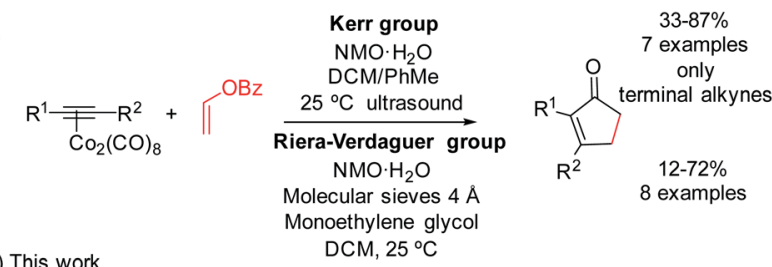

c) This work
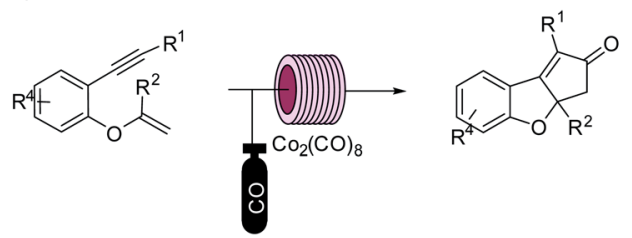

Scheme 1 Previous works using vinyl ethers in the PKr and our strategy. 

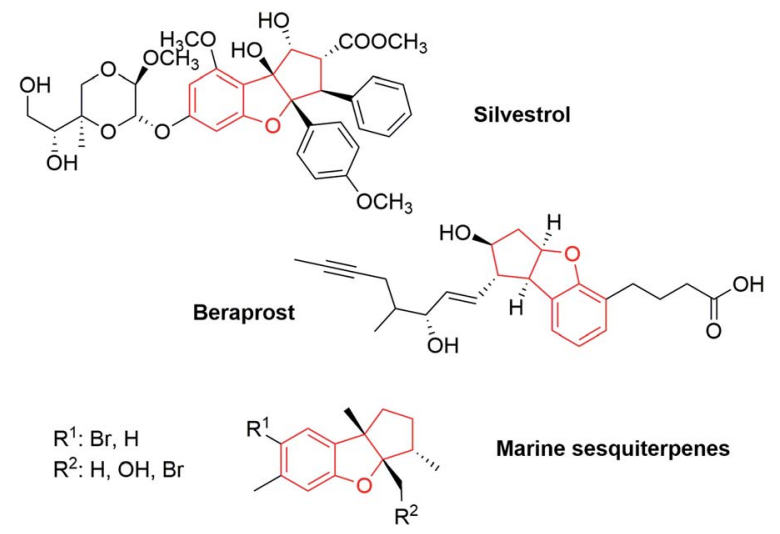

Fig. 1 Representative cycopenta benzofurans.

The use of 1,7-enynes tethered through an aromatic ring where the olefinic part is a vinyl ether has no precedents in $\mathrm{PKr}$ chemistry. These substrates are very reactive, but we envisioned that using flow technology we could find specific conditions to enable the PKr. This would provide a new efficient, scalable and versatile synthesis of tricyclic multi-substituted benzofurans.

The benzofuran structure is ubiquitous in bioactive molecules, natural products, pharmaceuticals and functional materials. The broad spectrum of pharmacological activity in individual benzofurans indicates that these compounds are of an undoubted interest. ${ }^{11}$ In addition, this motif is a useful scaffold in organic synthesis. Ohno and Arisawa recently reviewed the use of these, and other kinds of benzo-fused substrates to form heterocycles. ${ }^{12}$ Therefore, extensive attention has been paid to develop versatile methods for the synthesis of these structurally diverse heterocycles. ${ }^{13}$ Among tricyclic benzofurans that would be similar to our PausonKhand adducts, we highlight silvestrol, ${ }^{14}$ a natural product which is a potent inhibitor of Ebola virus replication; beraprost, ${ }^{15}$ a PGI analog; and natural sesquiterpenes, isolated from the red alga Laurencia and the sea hare Aplysia specie (Fig. 1). ${ }^{16}$

\section{Results and discussion}

We used substrate 1a as the model for the reaction optimization. This reaction produced variable amounts of the expected $\mathrm{PKr}$ product $\mathbf{2 a}$, the isomerized product $\mathbf{3 a}$ and the resulting product of a $[2+2+2]$ cycloaddition, 4a. This latter cycloaddition reaction has been already described with this catalyst at high temperatures. ${ }^{17}$ Preliminary experiments indicated that, in the presence of the catalyst and at high temperatures, there is an important decomposition of the starting material. Therefore, we introduced an internal standard (4,5-dibromo- $o$-xylene, $15 \mathrm{~mol} \%$ ) to calculate the amount of decomposition/ polymerization in each reaction. We compared similar conditions at temperatures from 120 to $210{ }^{\circ} \mathrm{C}$, both in batch and flow. Two batch conditions were studied for comparison under low (5 bar, batch 1) or high (20 bar, batch 2) CO pressure. We measured the amount of detected products and the selectivity towards the Pauson-Khand reaction (Fig. 2). With both

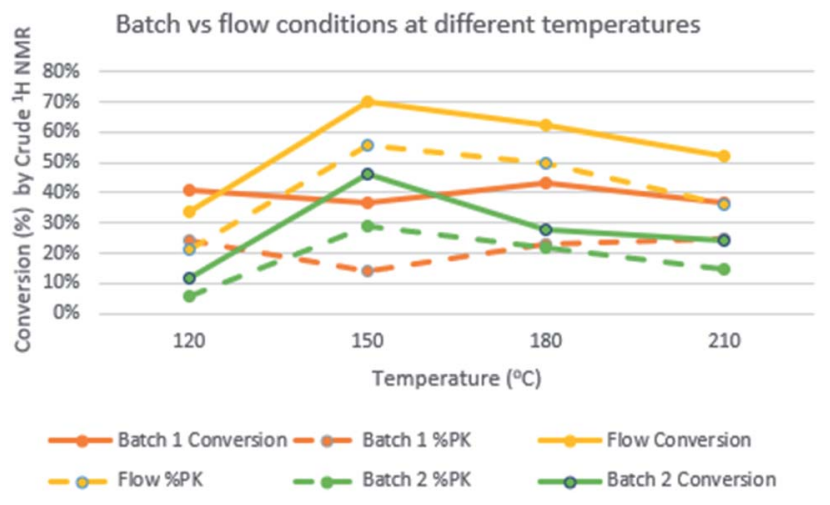

Fig. 2 Flow/batch comparison at different temperatures with $5 \mathrm{~mol} \%$ of $\mathrm{CO}_{2}(\mathrm{CO})_{8}$. Flow: 5 equiv. of $\mathrm{CO}, 7-15$ min of residence time, $28 \mathrm{bar}$ of system pressure. Batch $1: 5$ bar of $\mathrm{CO}, 45 \mathrm{~min}$ of reaction time. Batch 2: 20 bar of CO, $45 \mathrm{~min}$ of reaction time. Conversion refers to the NMR yield of $2 a+3 a+4 a$, while dashed lines only $2 a+3 a$.

methodologies, at $120^{\circ} \mathrm{C}$, the conversion was poor and starting material was still detected in the crude mixture. At $150{ }^{\circ} \mathrm{C}$ in flow we observed the highest conversion (70\%) but with poor selectivity towards $3 \mathrm{a}$, and at $180{ }^{\circ} \mathrm{C}$ there was a slightly better selectivity, not detecting $\mathbf{2 a}$, but with some more decomposition. This latter temperature was selected to optimize the rest of the flow parameters. We could confirm our initial hypothesis i.e. that we could benefit from the flow conditions to get fast reactions that avoid partially the decomposition of the starting material. In fact, yields in batch measured by NMR were very low and starting material was never recovered. Possibly, in the flow reactor we have achieved a chemical intensification due to the finding of a novel process window. ${ }^{18}$

Then, as shown in Table 1, flow parameters were optimized. Best results were achieved fixing the residence time to $13 \mathrm{~min}$ (entries 2-4) and using high pressures at $180{ }^{\circ} \mathrm{C}$ with 5 equiv. of CO (entry 4). The concentration was an important fact as high concentrations (entry 5) favored the $[2+2+2]$ side product, while low concentrations, (entry 6), decreased the speed of the reaction and increased decomposition. Reducing the amount of gas (entry 8) or the catalyst loading (entry 7) decreased the selectivity by forming more of the $[2+2+2]$ cycloadduct. With the conditions of entry 4, a long run was performed with $720 \mathrm{mg}$ and an isolated yield of $50 \%$ was achieved. This result shows a fall in the yield compared to the IS yield (64\%), that can be explained because of the instability of the final products. To check this point, we replicated three times the optimized reaction obtaining similar results.

Regarding the scope of the protocol, all the compounds with a terminal alkyne showed important decomposition and consequently poor to moderate yields (products 3b-e, 24-40\% yield, Fig. 3). An example using a vinyl thioether was also included (3f: $36 \%$ yield). In the same way, structures with two quaternary carbons surrounding the triple bond $(\mathbf{1 g}-\mathbf{h})$ did not show any reaction. The substrates with substitution at the external carbon of the vinyl ether $(\mathbf{1 i}-\mathbf{j})$, only produced $[2+2+2]$ cycloadducts, $1 \mathbf{i}$ formed the dimer $\mathbf{4 i}(21 \%)$, while $\mathbf{1 j}$ formed the cyclotrimerization product $\mathbf{4 j}$ (18\%). With substrates $\mathbf{1 k}-\mathbf{l}$ 
Table 1 Flow system set up and optimization of the PKr conditions for the synthesis of 3a

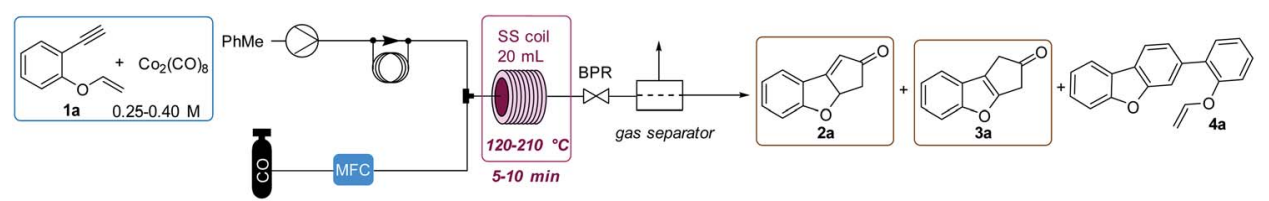

\begin{tabular}{|c|c|c|c|c|c|c|c|c|}
\hline Entry $^{a}$ & Temp. $\left({ }^{\circ} \mathrm{C}\right)$ & Res. time (min) & Conc. (M) & CO equiv. & $P$ (bar) & Cat. (mol\%) & $\%$ of conversion ${ }^{b}$ & $\%$ of $\mathbf{3 a}$ \\
\hline 1 & 150 & 11 & 0.25 & 5 & 28 & 5 & 70 & 56 \\
\hline 2 & 180 & 8 & 0.25 & 5 & 28 & 5 & 62 & 50 \\
\hline $4^{d}$ & 180 & 13 & 0.25 & 5 & 35 & 5 & 72 & 64 \\
\hline 5 & 180 & 10 & 0.40 & 5 & 28 & 5 & 35 & 5 \\
\hline 6 & 180 & 15 & 0.15 & 5 & 28 & 5 & 53 & 46 \\
\hline
\end{tabular}

${ }^{a}$ All reactions in PFR $(20 \mathrm{~mL})$. See ESI for system pump and MFC flows. ${ }^{b} \%$ of conversion is measured in the ${ }^{1} \mathrm{H}$ NMR spectrum of the crude mixture using 4,5-dibromo- $o$-xylene as internal standard. ${ }^{c} 0.12$ equiv. of DME were added as additive. ${ }^{d}$ A long run with $720 \mathrm{mg}(20 \mathrm{~mL}$ of volume) was performed to check the reliability of the IS, reaching an isolated yield of $50 \%$. In this experiment 4 a was isolated in $6 \%$ yield.

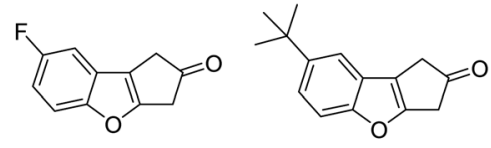

3b $57 \%(31 \%)$

3c $49 \%(30 \%)$<smiles>COc1ccc2oc3c(c2c1)CC(=O)C3</smiles>

3d $36 \%(24 \%)$<smiles>O=C1Cc2oc3ccc4ccccc4c3c2C1</smiles>

3e $65 \%(40 \%)$<smiles>C=COc1ccccc1C#C[As](C)(C)C#Cc1ccccc1OC=C</smiles><smiles>C#Cc1ccccc1O/C=C/C</smiles><smiles>COc1ccccc1-c1ccc2c(oc3ccccc32)c1C</smiles><smiles>C#Cc1ccccc1OC=C(C)C</smiles>

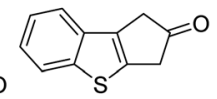

3f $53 \%(36 \%)$

\section{MS}<smiles>C1CC1</smiles> 
Table 2 Optimization of the PKr conditions for the synthesis of $2 m$

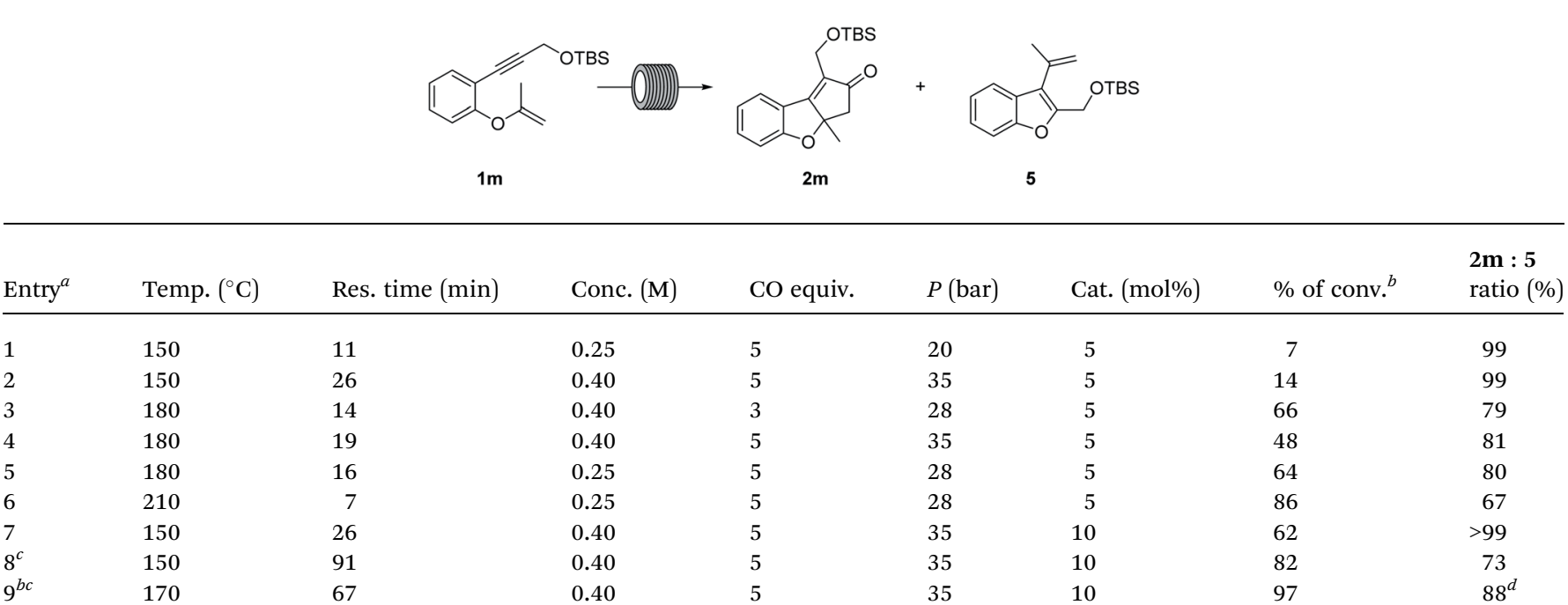

${ }^{a}$ All reactions in PFR $(20 \mathrm{~mL})$. See ESI for system pump and MFC flows. ${ }^{b} \%$ of conversion is measured in the ${ }^{1} \mathrm{H}$ NMR spectrum of the crude mixture. ${ }^{c} \mathrm{~A} 60 \mathrm{~mL}$ reactor was used in these entries. ${ }^{d}$ A long run with $1.21 \mathrm{~g}$ was performed, an isolated yield of $79 \%$ was achieved, total time: 102 minutes.<smiles>CC12CC(=O)C(C[18O])=C1c1ccccc1O2</smiles><smiles>CCCCC1=C2c3ccccc3OC2(C)CC1=O</smiles><smiles>CC12CC(=O)C(CCN3C(=O)c4ccccc4C3=O)=C1c1ccccc1O2</smiles>

2n $68 \%$<smiles>COc1ccc2c(c1)C1=C(CO[Se-])C(=O)CC1(C)O2</smiles>

2q $66 \%$
$2069 \%$<smiles>CC12CC(=O)C(CCBr)=C1c1ccccc1O2</smiles>

2p $71 \%$<smiles>CCCCOCC1=C2c3cc(F)ccc3OC2(C)CC1=O</smiles>

2s $74 \%$

Fig. 4 Scope of the reaction using substrates with internal substituted double bonds (isolated yields).

possibility of handling high temperatures, pressures and a hazardous gas. These conditions are difficult to reproduce in batch.

\section{Conclusions}

We have described for the first time an efficient Pauson-Khand reaction where the double bond is a vinyl ether. Good yields are achieved if the double bond is substituted at the internal position, whereas with other substrates the results are moderate. We believe that this reaction has been possible because of the use of continuous flow methodology, where the conditions have been intensified in relatively short time. This minimises the decomposition and allows the reaction. The process leads to cyclopentabenzofuranes which are very interesting scaffold's present in natural products and other interesting molecules.

\section{Author contributions}

Conceptualization of the work, J. P.-C. and G. D.; methodology, all authors; synthetic work, J. G.-L. and M. A.; writing-original draft preparation, J. G.-L.; writing-review and editing, J. P.-C. and G. D.; and funding acquisition, J. P.-C. All authors have read and agreed to the published version of the manuscript.

\section{Conflicts of interest}

There are no conflicts to declare.

\section{Acknowledgements}

Funding of this project by the Spanish MINECO, grant No. RTI2018-095588-B-I00 (Co-funded by European Regional Development Fund/European Social Fund, "Investing in your future") and FUSP-CEU (PC17/17) is acknowledged. J. G. thanks the Fundación San Pablo-CEU for a pre-doctoral fellowship.

\section{Notes and references}

1 (a) G. Domínguez and J. Pérez-Castells, in Science of Synthesis: Metal-Catalyzed Cyclization Reactions, ed. S. Ma, Thieme Chem, 2017, vol. 2, p. 99; (b) The Pauson-Khand Reaction: Scope, Variations and Applications, ed. R. R. Torres, Wiley, Hoboken NJ, 2012; (c) H. Lee and F. Kwong, Eur. J. Org. Chem., 2010, 2010, 789.

2 J. Garcia-Lacuna, G. Dominguez, J. Blanco-Urgoiti and J. Perez-Castells, Chem. Commun., 2017, 53, 4014.

3 J. García-Lacuna, G. Domínguez, J. Blanco-Urgoiti and J. Pérez-Castells, Org. Biomol. Chem., 2019, 17, 9489.

4 K. Asano, Y. Uesugi and J. Yoshida, Org. Lett., 2013, 15, 2398. 
5 For recent reviews on flow chemistry see: (a) B. Gutmann, D. Cantillo and C. O. Kappe, Angew. Chem., Int. Ed., 2015, 54, 6688; (b) M. B. Plutschack, B. Pieber, K. Gilmore and P. H. Seeberger, Chem. Rev., 2017, 117, 11796; (c) L. Rogers and K. F. Jensen, Green Chem., 2019, 21, 3481; (d) J. GarcíaLacuna, G. Domínguez and J. Pérez-Castells, ChemSusChem, 2020, 13, 5138; (e) M. Baumann, T. S. Moody, M. Smyth and S. Wharry, Org. Process Res. Dev., 2020, 24, 1802.

6 C. J. Mallia and I. R. Baxendale, Org. Process Res. Dev., 2016, 20, 327 .

7 (a) V. R. L. J. Bloemendal, M. A. C. H. Janssen, J. C. M. van Hest and F. P. J. T. Rutjes, React. Chem. Eng., 2020, 5, 1186; (b) R. Porta, M. Benaglia and A. Puglisi, Org. Process Res. Dev., 2016, 20, 2.

8 See for recent PK reviews with uncommon substrates: $(a)$ J. D. Ricker and L. M. Geary, Top. Catal., 2017, 60, 609; (b) J. Escorihuela, D. M. Sedgwick, A. Llobat, M. Medio-Simón, P. Barrio and S. Fustero, Beilstein J. Org. Chem., 2020, 16, 1662.

9 M. C. Croudace and N. E. Schore, J. Org. Chem., 1981, 46, 5357.

10 (a) A. Cabré, X. Verdaguer and A. Riera, Synthesis, 2017, 49, 3945; (b) W. Kerr, M. McLaughlin, P. Pauson and S. Robertson, J. Organomet. Chem., 2001, 630, 104.
11 H. Khanam and Shamsuzzaman, Eur. J. Med. Chem., 2015, 97, 483.

12 S. Ohno and M. Arisawa, J. Org. Chem., 2020, 85, 6831.

13 L. Chiummiento, R. D'Orsi, M. Funicello and P. Lupattelli, Molecules, 2020, 25, 2327.

14 N. Biedenkopf, K. Lange-Grünweller, F. W. Schulte, A. Weißer, C. Müller, D. Becker, S. Becker, R. K. Hartmann and A. Grünweller, Antiviral Res., 2017, 137, 76.

15 S. Umemiya, D. Sakamoto, G. Kawauchi and Y. Hayashi, Org. Lett., 2017, 19, 1112.

16 S. Biswas, A. Ghosh and R. V. Venkateswaran, J. Org. Chem., 1990, 55, 3498.

17 J. García-Lacuna, G. Domínguez, J. Blanco-Urgoiti and J. Pérez-Castells, Org. Lett., 2018, 20, 5219.

18 (a) V. Hessel, D. Kralisch, N. Kockmann, T. Noël and Q. Wang, ChemSusChem, 2013, 6, 746; (b) S. Borukhova and V. Hessel, in Process Intensif. Green Chem., ed. K. Boodhoo and A. Harvey, Wiley, Chichester, UK, 2013, pp. 91-156; (c) T. Razzaq, T. N. Glasnov and C. O. Kappe, Chem. Eng. Technol., 2009, 32, 1702.

19 (a) S. Ohno, J. Qiu, R. Miyazaki, H. Aoyama, K. Murai, J. Hasegawa and M. Arisawa, Org. Lett., 2019, 21, 8400; (b) N. Sakiyama, K. Noguchi and K. Tanaka, Angew. Chem., Int. Ed., 2012, 51, 5976. 